\title{
Study on the Control Techniques for the SAPFs: A Comprehensive Analysis
}

\author{
N. Keerthi*1, A. Pandian ${ }^{2}$ \\ ${ }^{1}$ Research Scholar, Department of Electrical \& Electronics Engineering, KLEF, Vaddeswaram, India \\ ${ }^{2}$ Professor, Department of Electrical \& Electronics Engineering, KLEF, Vaddeswaram, India \\ *Corresponding author, e-mail: keerthi.nakka1990@gmail.com
}

\begin{abstract}
The electrical power structure is polluted due to the usage of non-linear loads at the utilization side. Power engineers and consumers constantly look for the best and economical solutions to improve the power quality. Current harmonics and neutral current issues are the important power quality (PQ) problems in power distribution systems. The shunt active power filter (SAPF) technology is a best technology to minimize current harmonics, neutral current issues and reactive power problem. However the performance of SAPF is definitely dependents on its control techniques. So the applied control techniques have to perform precisely and quickly. This paper gives a comprehensive analysis on different types of control techniques which are employed for proper controlling of SAPF under ideal voltage (sinusoidal) conditions. Continuous time, discrete time, PWM, DC-link voltage control, and synchronizer techniques are studied briefly. The relevant strengths and weaknesses are also described for the mostly used control techniques to provide better solutions for researches and power engineers.
\end{abstract}

Key words: SAPFs, PQ, Harmonics, Control Methods

\section{INTRODUCTION}

Ideal response (harmonic and ripple free) and frequency are the major electrical parameters which are subjected to the variations due to the equipment disturbances, load changes, and faults caused by many events. Most of these events vary randomly with time and will occur naturally and with human activities. The non-linear loads present in the electrical networks generally produce the current harmonics in the system [1]. These current harmonics seriously effects the utensils such as, overheating the electric drives, transformers and reactive power regulators (capacitors) used for power factor correction. Additionally, the harmonics can also be the reason for voltage flickers and electromagnetic interference issues. Hence, devices are needed to improve the above said parameters.

Over the years, various solutions have been implemented to minimize these harmonics related issues, such as passive filters which are the combination of inductors and capacitors. These filters are very simple; but have major drawbacks such as bulky in size, expensive and have limited ability to compensate the harmonics [2]. Therefore the active filters are came into the picture overcome the above mentioned disadvantages of passive filters and also very reliable to improve the system power quality. The active filter mainly performs the tasks such as, mitigation of harmonics, active and reactive powers regulation and power factor improvement.

A large number of publications are reported on the active power filters (APFs) for power quality (PQ) measurements, analysis and improvements, harmonic effects and reactive power issues in the electrical systems. Shunt active power filter (SAPF) is considered as an ideal device for mitigating power quality problems. In addition, the SAPFs also have the capability to smooth voltage flickers and control the terminal voltages in distributed systems. SAPFs are existing in two distinct forms and they are categorized based on the inverter topology engaged, namely voltage source inverter (VSI) and current source inverter (CSI). However, for the SAPFs, VSIs are the mostly favored because of their compact sizes and less implementation price. On the other hand, VSIs are the best topologies for the implementation of multilevel and multi-step SAPFs which significantly improves system performance in harmonics reduction. Generally, the SAPFs are classified into two types, single-phase and three-phase systems, specifically, single-phase two-wire $(1 \mathrm{P} 2 \mathrm{~W})$, three-phase three-wire $(3 \mathrm{P} 3 \mathrm{~W})$, and three-phase four-wire $(3 \mathrm{P} 4 \mathrm{~W})$ configurations, based on the types of nonlinear loads in grid systems. Some of the non-linear loads such as TVs, ovens, ACs, domestic lights, computer power supplies, printers etc can cause power quality issues at the consumer side [3-5]. For that reason, this document mainly focuses only on the VSI used as SAPFs.

The performance of SAPFs is absolutely depends on the control techniques applied. So these control techniques working have to be very precise and fast. Different VSI based SAPF control techniques have been examined and reported in this paper to satisfy the power quality requirements of the nonlinear loads. Controller working functions such as harmonic current extraction, DC-link voltage regulation, PWM generation, and current control of SAPFs are reported in detail. In general, these control techniques are illustrated for the three-phase supply based SAPFs however, these can also be applied for single-phase supply based SAPFs with minor modifications. 


\section{STRUCTURE OF SAPF}

Nowadays, the conception of power quality (PQ) has turned into an important measure for the power engineers, researchers and customers because of quick boost in the utilization of non-linear loads in the power distribution systems. Passive filtering techniques have utilized in the past to mitigate the PQ issues. Nevertheless, these passive filters are extremely affected by the source impedance. Moreover, these filters are also suffered with large filters size, series and parallel resonances, which raise the source harmonics in the current etc. A lot of research has been done in all over the world, to identify a better solution to compensate the above mentioned problems and to improve the power quality.

A voltage source inverter (VSI) with a DC-link capacitor or a current source inverter (CSI) with an inductor are used as shunt type active power filters which are connected at point of common coupling (PCC). Because of the advantages of SAPFs, it is the most extensively worn configuration for the minimization of harmonics in the current, regulation of reactive power and compensation of neutral current in the power system. For this reason, many industries, and other distribution companies are broadly implementing from the past two decades. Required AC voltages have been generated by the VSI converter based on the reference signals and the compensation. A series inductor is connected at the output of VSI in order to reduce the ripples due to switching and to enhance the wave shape of current. By accurate tuning of phase and amplitudes of VSI produced voltages, the SAPF performance will be enhanced which also improves the entire system performance. The single-line diagram of SAPF is revealed in figure 1.

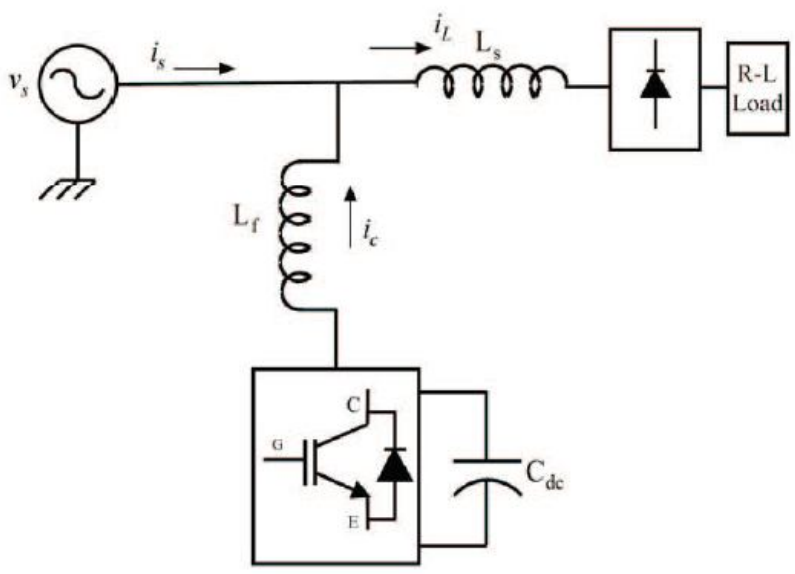

Figure 1: Single-line representation of shunt active power filter with RL load.

\section{CONTROL TECHNIQUES FOR SAPFS}

The performance of a SAPFs are mainly depends on the effectiveness of its control techniques. This paper represents the detailed control structure of SAPF with their key functions. The control methods took very important part in the compensating procedure. The performance of SAPF mainly depends on the precise generation of the reference signal for harmonic extraction. To control SAPFs a number of control techniques have been developed for various operating conditions. This section clearly explains the types and classifications of different control methods used for SAPFs connected to sinusoidal grid voltage conditions. Figure 2 shows the detailed tree diagram of classification of control methods for SAPFs. This classification is majorly divided into five categories in which first two categories describe about the estimation methods with analog and discrete times respectively.

\subsection{Reference current synthesis:}

Reference signal synthesis, which is a continuous time based control technique, is divided into two methods namely i) Low-pass filter and ii) High-pass filter. The desired reference signal can be generated by filtering and subtracting the fundamental component from the total load current [6]. The high-pass filters are used for reducing the lower order harmonics in the nonlinear load current. However, this control method is vulnerable to noise. To minimize this issue, low-pass filters are preferred over the high-pass filtering techniques as it reduces the differentiation effect in the filtered signal. But, this method suffers with huge amplitude and phase-angle errors.

\section{REFERENCE CURRENT GENERATION}

The harmonics estimation or reference current generation techniques are implemented because of the major disadvantage of the synthesis methods which includes amplitude and phase errors. The current harmonics detection rate in the distribution system is the major concern to estimate the PQ issues. Hence, the performance of the SAPF is seriously based on fast and accuracy of the reference signal generation $i_{\text {ref }}$. These techniques are implemented in discrete time domain and are classified into four major types. They are

i) Frequency-domain,

ii) Time-domain,

iii) Learning techniques and

iv) Other methods.

Frequency domain techniques are mainly based on the Fourier analysis (FFT or DFT) principle and estimate the harmonics by measuring in the distorted load current [7], [8]. The harmonic content is extracted from the distorted load current and is separated from the measured signal. This current is again recreated as a time based reference current signal. Normally, the SAPFs switching frequency is chosen more than two times of the maximum harmonic frequency to achieve better harmonic elimination [9]. Frequency domain techniques can be designed for both $1 \mathrm{P}$ (single phase) and 3P (three phase) distribution systems. Mostly used frequency domain control techniques are Kalman filter, Fast Fourier Transforms (FFT), modified Fourier series, sine 
multiplication, RDFT, STFT and Wavelets (WT) [10]. The major difficulty faced by frequency domain techniques are the associated time delay (integral), takes more time for calculation; thus appropriate for gradually changeable loads. The sub-divisions of frequency domain techniques are shown in figure 2 .

Time domain control methods are easy and simple to develop in the real-time systems. Nowadays, many researchers and power engineers across the world are working on the time-domain control methods due to their robustness, fast response, less calculations and simple to implement compared with other control techniques. These techniques extract the harmonics based on the principle of deriving the reference current instantaneously from the load current. Time domain control techniques are generally adopted in 3P networks are $\mathrm{P}-\mathrm{Q}$ theory or instantaneous reactive power theory (IRPT) [2], Instantaneous symmetrical component theory (ISCT) [42], Synchronous reference frame (SRF) [12], power balance theory [13], unit template technique [14], Enhanced phase locked loop (EPLL)-based control algorithm [15] and Icose control algorithm [16]. A few techniques mostly used in 1P networks are 1P-PQ theory, 1P-dq theory, fictitious power compensation technique, and DC-link energy balance method etc.

The PQ (IRPT) theory instantaneously (without any delay) calculates the active and reactive powers. This theory converts $3 \mathrm{P}$ voltage/current variables into $2 \mathrm{P}$ voltage/current variables by using the Clark transformation [2]. For the ISCT control, the average load power will be calculated using the 3P load currents and voltages. Similarly, the PF of the load is calculated and reference current signal angle will be estimated [11]. Similar to the PQ theory, with PLL block the SRF technique compensates the harmonics and synchronizes with the grid voltages. This control method is very efficient under non-sinusoidal grid voltage conditions [12]. However, tuning of PLL parameters is the biggest challenge to the power engineers [15]. In the power balance algorithm, the 3P voltages and the DC-capacitor voltage are sensed, which is simple to develop [13]. The unit template (PI-controller) control method is robust, and simple to implement. It also reduces the load on the processors, actively balances the unbalanced loads and improves the PF with better reactive power compensation [14]. The traditional PLL provide worse results for extremely unbalanced load and/or non-sinusoidal grid voltage conditions. But, the EPLL control method has better synchronism capability by making phase difference zero between the grid voltage and current which enhances the performance of SAPF [15]. The ICose technique uses sample and hold circuit for finding the phase angle of load current at zero crossing point to ensure the high PF [16]. The DC-link energy balance control method is very robust, easy to implement, simple and easy to develop for 1P systems [17].

A different technique to remove the desired harmonic contents is by using the learning techniques. The existing techniques are optimization, Artificial Neural Networks (ANN) and Genetic Algorithms (GA) etc. These techniques are usually applied in $2 \mathrm{C}$ based SAPFs to extract the harmonic content to create the switching pattern of the reference signal [18]. However, these techniques suffer with complexity, difficult computations, take long time for computation, hard to implement and humiliate the dynamic response of the system [19].

The control techniques apart from the abovementioned categories are also presented as other methods for harmonic extraction. These techniques are developed with small changes made to the abovementioned algorithms, to attain improved performance over their respective ancestors. In the SRF method, the LPFs are replaced with sliding window Fourier analysis (SWFA) can be called as dq with Fourier (dqF) [20]. Similarly, if the LPFs are replaced with wavelet transforms (WT) [21] then it is called as simplified SRF (SSRF). These control techniques has shown a considerable improvement in the performance under the dynamic and steady-state conditions. The modifications made in the IRPT control techniques are, addition of fuzzy logic controller (FLC) [22], LPFs are replaced by sliding window Fourier analysis (SWFA) can be called as pq with Fourier (pqF) [23]. One more change is also made for the ANN control method which is called as FAC - ANN (fundamental active current) [24]. However, this control technique is only applied for $1 \mathrm{P}$ distribution networks. The FAC -ANN control method has shown the improved performance under dynamic and steady-state conditions.

\section{CURRENT CONTROL TECHNIQUES}

The PWM control methods are also very important in the harmonics compensation of SAPF by creating appropriate pulses for the active switches to enhance the compensating performance of the system. The most used PWM methods are sinusoidal PWM (SPWM), where the sinusoidal signal (reference) is compared with saw-tooth signal (carrier) to produce the gate pulses; deadbeat controller, where the instantaneous voltages are used for reference signal generation which took more time; space vector PWM (SVPWM), where the switching combinations are modified with different modulation index; sliding mode controller, which works based on the state space analysis of the system $[25,26]$; single band hysteresis current controller (SBHCC), which is accurate, quick in response and robust but suffers with variable switching frequency; and double hysteresis current controller (DHCC), which contains two bands for upper and lower switches respectively [27]. DHCC is operated with lower frequency over the SBHCC method which minimizes the switching losses of the system [28, 29].

\subsection{DC-link voltage regulation}

Maintaining the steady voltage magnitude at the DC-link (capacitor) is also an important factor to inject the required injection current $\left(i_{f}\right)$ into the unbalanced distribution system. 


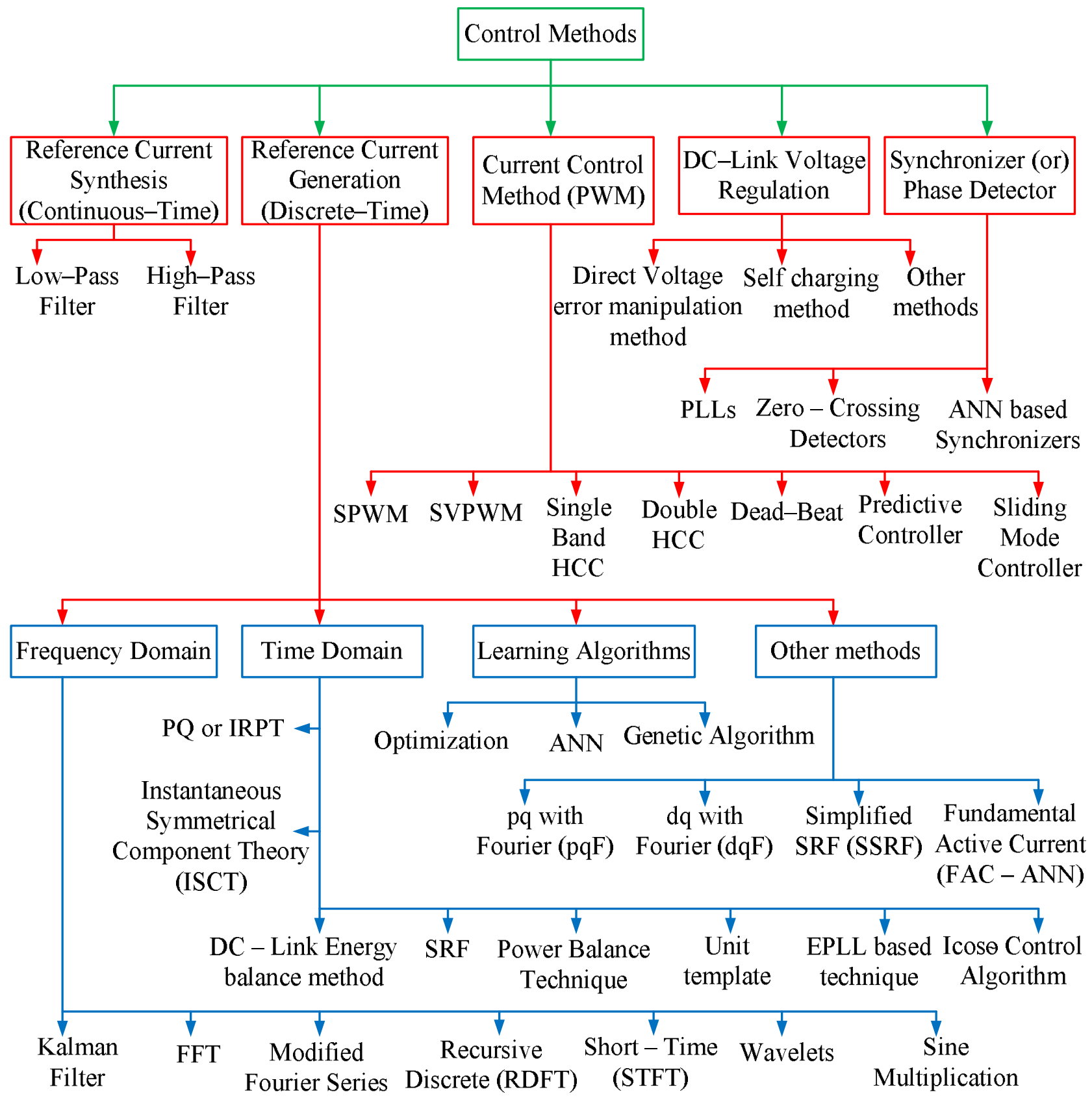

Figure 2: Classifications of control techniques for SAPF

By regulating the active power of the SAPF, the DC-link voltage will be maintained constant which is accomplished by equating the switching losses of SAPF to its active power. So, as stated in earlier sections, the required current magnitude $\left(I_{d c}\right)$ to charge the DC-link capacitor, of the DC-link charging current $i_{d c}$ can be estimated using resultant error. The essential current magnitude $i_{d c}$ is the quantity of $I_{d c}$ required by the SAPF to normalize its switching losses so as to maintain the DC-link voltage of the capacitor $V_{d c}$ at the constant reference value. So far, a number of DC-link voltage regulation methods have listed in the literature. Basically, these are categorized as direct voltage error manipulation [30] self-charging methods [31] and the other control techniques $[2,31]$ (see Figure 2).

\subsection{Synchronizer}

In the SAPFs functioning, synchronizers or phase detectors are also needed to detect the phase operation of SAPF with respect to grid system. The synchronizer block converters the input voltage signal $v_{S}$ in to a synchronization phase (sine and cosine functions) $(\varnothing)$. This helps, the injected filter current generated by SAPF for a proper synchronization with the input voltage signal $v_{S}$. In addition, it also provides the synchronization angle for the Park transformation in the SRF based techniques. It is important that some distinctive SAPF controllers do not need explicit PLL or synchronization methods. These methods are classified as phase-locked loops (PLLs) [32], ANN-based synchronizers [33], and zero-crossing detectors (ZCDs) [34]. 
The exploitation of renewable energy sources growing gradually and grid management using the power electronic topologies contribute significant part. The best possible operation of power converters utilized in grid tied PV systems; this is the feature scope of the research on SAPFs.

\section{CONCLUSION}

The main intention of this paper is to provide better motivation and solutions for the researches in SAPFs area. A complete study on the control techniques used in SAPF is reported in this paper for enhancing the PQ at the both consumer and supplier side of the electrical system. The importance of SAPFs and their control, advantages, classification and key functions of SAPFs are briefly given. Different features of control techniques used for SAPFs are presented. Various classifications of control techniques such as continuous-time, discrete-time, PWM, DC-link voltage control, and synchronizer are reported clearly. The relevant strengths and weaknesses are also listed for the most of control techniques. The utilization of renewable energy sources in the grid based SAPFs is the future scope of this area.

\section{REFERENCES}

1. Nagi Reddy. B, O. Chandra Sekhar, M. Ramamoorty, "Implementation of zero-current switch turn-ON based buck-boost buck type rectifier for low power applications". International journal of electronics, https://www.tandfonline.com/doi/full/10.1080/00207217 .2019.1582711. Vol.106, No.8.

2. M. S. Karbasforooshan and M. Monfared, "Design and implementation of a single-phase shunt active power filter based on pq theory for current harmonic compensation in electric distribution networks," in IECON 2017 - 43rd Annual Conference of the IEEE Industrial Electronics Society, Oct 2017, pp. 6389-6394. https://doi.org/10.1109/IECON.2017.8217113

3. M. Rashid, Power Electronics: Circuits, Devices, and Applications. Pearson, 2009. [Online]. Available: https://books.google.com.mx/books?id=-WqvjxMXClAC.

4. Nagi Reddy. B, A. Pandian, O. Chandra Sekhar, M. Rammoorty, "Design of Non-isolated integrated type AC-DC converter with extended voltage gain and high power factor for Class-C\&D applications". International Journal of Recent Technology and Engineering (IJRTE), Vol. 7, No. 5, Jan 2019, pp 230-236.

5. Nagi Reddy. B, O. Chandra Sekhar, M. Ramamoorty, "Analysis and implementation of single-stage buck-boost buck converter for battery charging applications"; Journal of Advanced Research in Dynamical and Control Systems, Vol. 10, No. 4, April 2018, pp 446-457.

6. W. M. Grady, M. J. Samotyj, and A. H. Noyola, "Survey of active power line conditioning methodologies," IEEE Trans. Power Delivery, vol. 5, pp. 1536-1542, July 1990. https://doi.org/10.1109/61.57998

7. J. W. Cooley and J. W. Tukey, "An algorithm for the machine calculation of complex Fourier series," Math. Comput., vol. 19, no. 2, pp. 297-301, 1965. https://doi.org/10.2307/2003354

8. S. M. Williams and R. G. Hoft, "Adaptive frequency domain control of PWM switched power line conditioner,' IEEE Trans. Power Electron., vol. 6, no. 4, pp. 665-670, 1991. https://doi.org/10.1109/63.97766

9. Masoum M.A.S, Fuchs E.F, "Power Quality in Power Systems and Electrical Machines", 2nd edition, Elsevier Science \&Technology Books: 2015.

10. Bhattacharya A, Chakraborty C, Bhattacharya S, "Shunt compensation-Reviewing traditional methods of reference current generation", IEEE Industrial Electronics magazine 2009.

11. U. K. Rao, M. K. Mishra and A. Ghosh, "Control strategies for load compensation using instantaneous symmetrical component theory under different supply voltages," IEEE Trans. Power Del., vol. 23, no. 4, pp. 2310-2317, Oct. 2008. https://doi.org/10.1109/TPWRD.2008.923053

12. M. A. Kabir and U. Mahabub, "Synchronous detection and digital control of shunt active power filter in power quality improvement," in Proc. of Power and Energy Conference at Illinois (PECI), pp. 1-5, pp. 1-5, Feb. 2011.

13. A.A. Girgis, W.B. Chang and E.B. Makram, "A digital recursive measurement scheme for online tracking of power system harmonics", IEEE Trans. Power Del., vol. 6, no. 3, pp. 1153-1160, 1991.

https://doi.org/10.1109/61.85861

14. M. I. Milanes, E. R. Cadaval and F. B. Gonzalez, "Comparison of control strategies for shunt active power filters in three-phase four-wire systems," IEEE Trans. Power Electron., vol. 22, no. 1, pp. 229-236, Jan. 2007.

15. A. J. Viji and T. A. A. Victoire, "Enhanced PLL based SRF control method for UPQC with fault protection under unbalanced load conditions", Inter., J., Electr., Power \& Energy Syst., vol. 58, pp.319-328, 2014.

16. B. Singh, A. Chandra, and K. Al-Haddad, Power Quality: Problems and Mitigation Techniques. Wiley, 2014. https://doi.org/10.1002/9781118922064

17. S. Biricik, S. Redif, S. K. Khadem and M. Basu, "Improved harmonic suppression efficiency of single-phase APFs in distorted distribution systems", Inter., J., Electron., vol. 103, no. 2, pp. 232-46, 2016.

18. Welsh M, Mehta P, Darwish M.K, "Genetic algorithm and extended analysis optimisation techniques for switched capacitor active filters-Comparative study", IEEE Proc. Electr. Power Appl. 2000, 147, $21-26$.

19. Ibrahim W.R.A, Morcos M.M, "Artificial intelligence and advanced mathematical tools for power quality applications: A survey", IEEE Trans. on Power Delivery. 2002, 17, 668-673. https://doi.org/10.1109/61.997958 
20. Areerak K.-L, Areerak K.-N, “The comparison study of harmonic detection methods for shunt active power filters", World Acad. Sci. Eng. Technol. 2010, 4, 204-209.

21. K. G. Firouzjah, A. Sheikholeslami, M. R. Karami Mollaei, M. Khaleghi, "A New Harmonic Detection Method for Shunt Active Filter Based on Wavelet Transform," Journal of Applied Sciences Research, pp. 1561-1568, 2008.

22. Eskandarian N, Beromi Y.A, Farhangi S, "Improvement of dynamic behavior of shunt active power filter using fuzzy instantaneous power theory", Journal of Power Electronics, vol. 14, 1303-1313, 2014.

23. Tiyarachakun S, Areerak K, Areerak K, "Instantaneous power theory with Fourier and optimal predictive controller design for shunt active power filter", Model. Simul. Eng. 2014.

24. Zainuri M.A.A.M, Radzi M.A.M, Soh A.C, Mariun N, Rahim N.A, Hajighorbani S, "Fundamental active current adaptive linear neural networks for photovoltaic shunt active power filters", Energies, vol. 9, 397, 2016. https://doi.org/10.3390/en9060397

25. S. L. Jung and Y. Y. Tzou, "Sliding mode control of a closed-loop regulated PWM inverter under large load variations", In Power Electronics Specialists Conference, pp. 616-622, 1993.

26. A. Çetin and M. Ermis, "VSC-based D-STATCOM with selective harmonic elimination", IEEE Trans., Ind., Appl., vol. 45, no. 3, pp.1000-1015, 2009.

27. A. K. Panda and R. Patel, "Adaptive hysteresis and fuzzy controlled based shunt active power filter resistant to shoot-through phenomenon," IET Power Electron., vol. 8, no. 10, pp. 1963-1977, April 2015.

28. F. Wu, B. Sun, K. Zhao and L. Sun, "Analysis and solution of current zero-crossing distortion with unipolar hysteresis current control in grid connected inverter," IEEE Trans. Ind. Electron., vol. 60, no. 10, pp. 4450-4457, 2013.

29. P. A. Dahono, "New hysteresis current controller for single-phase fullbridge inverters," IET Power Electron., vol. 2, no. 5, pp. 585-594, 2009. https://doi.org/10.1049/iet-pel.2008.0143

30. Mikkili S, Panda A.K, "Simulation and real-time implementation of shunt active filter id-iq control strategy for mitigation of harmonics with different fuzzy membership functions", IET Power Electron., vol. 5, pp. 1856-1872, 2012.

31. Zainuri M.A.A.M, Radzi M.A.M, Soh A.C, Mariun N, Rahim N.A, "DC-link capacitor voltage control for single-phase shunt active power filter with step size error cancellation in self-charging algorithm", IET Power Electron., vol. 9, pp. 323-335, 2016.

32. Monfared M, Golestan S, Guerrero J. M, "A new synchronous reference frame-based method for single-phase shunt active power filters", J. Power Electron., vol. 13, 692-700, 2013.

https://doi.org/10.6113/JPE.2013.13.4.692

33. Rahman N.A, Radzi M.A.M, Mariun N, Soh A.C, Rahim N.A, "Integration of dual intelligent algorithms in shunt active power filter", Proceedings of the IEEE Conference on Clean Energy and Technology (CEAT), Malaysia, pp. 259-264, November 2013. https://doi.org/10.1109/CEAT.2013.6775637

34. Chauhan S.K, Shah M.C, Tiwari R.R, Tekwani P.N, "Analysis, design and digital implementation of a shunt active power filter with different schemes of reference current generation", IET Power Electron., vol. 7, pp. 627-639, 2014.

https://doi.org/10.1049/iet-pel.2013.0113 